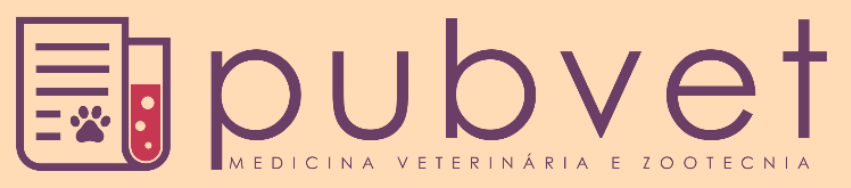

https://doi.org/10.31533/pubvet.v14n6a585.1-7

\title{
Terapia Neural no tratamento de ruptura de tendão calcâneo comum canino: relato de caso
}

\author{
Bruna Aparecida Lima Gonçalves ${ }^{1 *} \bullet$, Leonardo Rocha Vianna ${ }^{2}$, Ana Cristina Ribeiro Mendes ${ }^{3} \bullet$, \\ Ana Paula Carvalho Rocha ${ }^{4} \bullet$, Deise Dimas Muniz ${ }^{4}$ \\ ${ }^{I}$ Médica Veterinária formada pela Pontifícia Universidade Católica de Minas Gerais Betim (PUC MINAS), Mestre em Ciência Animal pela \\ UFMG, acupunturista, terapeuta neural. ${ }^{2}$ Médico Veterinário formado na UFMG, Mestre em clínica e cirurgia pela UFMG, acupunturista, \\ terapeuta neural, médico chinês, Ten. Coronel médico veterinário reformado da PMMG e especialista em medicina natural. \\ ${ }^{3}$ Professora da PUC MINAS, Departamento de Medicina Veterinária, Betim-MG Brasil. Mestre em Fisiologia e Farmacologia pela UFMG. \\ ${ }^{4}$ Graduandas da Pontifícia Universidade Católica de Minas Gerais, Departamento de Medicina Veterinária, Betim-MG Brasil. \\ *Autor para correspondência,E-mail: bruna_alg@yahoo.com.br
}

\begin{abstract}
Resumo. A Terapia Neural (TN) é considerada uma terapia integral que ajuda na reorganização do organismo para que este restabeleça seu estado de equilíbrio e auto cura. Um dos objetivos é o restabelecimento do potencial de membrana celular por isto é indicada para inúmeras enfermidades. É uma técnica utilizada para eliminar transtornos causados por diversos fatores e baseia-se na utilização de anestésicos locais, em baixas concentrações. $\mathrm{O}$ efeito esperado do uso do anestésico local na TN é de estimulação das propriedades elétricas da célula restabelecendo o potencial fisiológico e a atividade energética do organismo. O caso relatado tem como objetivo demonstrar a efetividade da Terapia Neural na cicatrização do Tendão Calcâneo Comum (TCC) de um cão. Essa é uma afecção comumente causada de forma traumática por objetos perfuro cortantes ou trauma direto, que pode trazer grande comprometimento da função locomotora caso não haja uma intervenção adequada.
\end{abstract}

Palavras chave: lesão de tendão, procaína, tendão calcâneo comum, terapia neural

\section{Neural therapy in the treatment of canine common calcaneal tendon rupture: case report}

\begin{abstract}
Neural Therapy (NT) is considered an integral therapy that helps in reorganizing the body so that it restores its state of balance and self-healing. One of the objectives is to restore the potential of the cell membrane, which is why it is indicated for numerous diseases. It is a technique used to eliminate disorders caused by several factors and is based on the use of local anesthetics, in low concentrations. The expected effect of using the local anesthetic in NT is to stimulate the electrical properties of the cell, restoring the physiological potential and the energetic activity of the organism. The reported case aims to demonstrate the effectiveness of Neural Therapy in healing a dog's Common Calcaneal Tendon. This is a condition commonly caused traumatically by sharp objects or direct trauma, which can cause major impairment of locomotor function if there is no adequate intervention.
\end{abstract}

Keywords: common calcaneal tendon, neural therapy, procaine, tendon injury

\section{Terapia neural en el tratamiento de la ruptura del tendón calcáneo común canino: reporte de un caso}

Resumen. La Terapia Neural (TN) se considera una terapia integral que ayuda a reorganizar el organismo para que restablezca su estado de equilibrio y autocuración. Uno 
de los objetivos es restaurar el potencial de la membrana celular, por lo que está indicado para numerosas enfermedades. Es una técnica utilizada para eliminar los trastornos causados por varios factores y se basa en el uso de anestésicos locales, en bajas concentraciones. El efecto esperado del uso del anestésico local en NT es estimular las propiedades eléctricas de la célula, restaurando el potencial fisiológico y la actividad energética del organismo. El caso reportado tiene como objetivo demostrar la efectividad de la Terapia Neural en la curación del tendón calcáneo común (TCC) de un perro. Esta es una condición comúnmente causada traumáticamente por objetos afilados o trauma directo, que puede causar un deterioro importante de la función locomotora si no hay una intervención adecuada.

Palabras clave: lesión del tendón, procaína, tendón calcáneo común, terapia neural

\section{Introdução}

A Terapia Neural (TN) surgiu inicialmente como terapia dos anestésicos locais ou injetáveis com os russos Pavlov e Speransky no século XIX e em 1905 com a descoberta do primeiro anestésico sintético, a procaína. Em 1906 Spiess pôde observar o efeito curativo da procaína em processos inflamatórios, onde feridas cicatrizaram com maior rapidez e com menor grau de complicações (Burrel, 2008; Castro, 2011). Em 1925 a terapia dos anestésicos foi batizada como Terapia Neural pelos irmãos Huneke, médicos alemães e pesquisadores que aprofundaram a pesquisa e prática da Terapia Neural (Burrel, 2008; De La Torre \& Bonilla, 2012; Fischer, 2000). A TN, junto com outras práticas complementares, foi reconhecida pelo governo colombiano em 1992 e, desde 2001, a faculdade de Medicina da Universidade Nacional da Colômbia a incorporou em seu curso de extensão (Gonçalves et al., 2019).

A Terapia Neural ajuda na reorganização do organismo de modo que possa surgir uma nova ordem de informação através do restabelecimento do potencial de membrana celular. Esta terapia ajuda o corpo a ativar seus processos de auto cura quando há uma desordem no organismo capaz de provocar doença (Fischer, 2000; Koval, 2014). Um estímulo irritativo em qualquer parte do sistema nervoso, seja ele central e/ou periférico, pode causar um desequilíbrio no organismo e como consequência provocar enfermidades (De La Roche, 1981; Gonçalves et al., 2019; Illera \& Cárdenas, 2011). É considerada como uma terapia integral, trata o organismo como um todo, desta forma as indicações incluem inúmeras enfermidades como: reumáticas, neurológicas, inflamatórias, infecciosas, alérgicas, afecções dermatológicas, entre outras (De la Torres Rosés \& Mendoza, 2008).

Uma lesão tecidual tem capacidade de gerar campos elétricos divergentes, que influenciam na despolarização e repolarização da membrana das células (Cruz \& Naffah, 2011). O funcionamento correto da bomba de sódio-potássio é uma condição importante para que se tenha o funcionamento normal da transmissão nervosa, organizando um estado de despolarização e repolarização permanentes. Quando ocorrem estímulos frequentes ou intensos que alteram a funcionalidade correta do sistema, pode ser provocado um estado de despolarização permanente ocasionando em um mau funcionamento celular (tecidual), que irá produzir campos interferentes, enfraquecendo o organismo em parte ou como um todo, podendo causar enfermidades (Burrel, 2008; Vianna \& Gonçalves, 2016). Em condições normais a célula possui um potencial de membrana de 40-90 milivolts, mas quando sofre estímulos irritativos entra em estado de despolarização. A procaína possui um potencial de 290 milivolts e sua aplicação faz com que a célula volte ao estado de repolarização, onde estabiliza seu potencial de ação de membrana (Burrel, 2008; Castro, 2011; Cruz \& Naffah, 2011).

A Terapia Neural baseia-se na utilização de anestésicos locais, como a procaína e lidocaína em baixas concentrações, que agem na reorganização do funcionamento fisiológico celular. Os locais de aplicação são escolhidos após o levantamento do histórico de vida do paciente. A procaína foi a droga de escolha por ser metabolizada no plasma pelas pseudocolinesterases e com excreção renal, sendo eliminada pela urina (Burrel, 2008; Vianna \& Gonçalves, 2017). A procaína é normalmente utilizada nas concentrações de $0,35 \%$ a $1,0 \%$ e a lidocaína nas concentrações de $0,3 \%$ e $0,5 \%$ em determinadas regiões como: pontos dolorosos, pontos gatilhos, cicatrizes, zonas de emergência nervosa, pontos de acupuntura, intraarticular, intraperitoneal, intravenosa (Gonçalves et al., 2019). 
A acupuntura e a Terapia Neural são tratamentos que ativam os mecanismos compensatórios e reguladores do organismo (Draehmpaehl \& Zohmann, 1997; Molano et al., 2014). O estímulo das terminações nervosas pela acupuntura leva uma mensagem até o sistema nervoso central, onde é reconhecido e traduzido em três níveis: nível hipotalâmico que ativa o eixo-hipotálamo-hipófise que gera liberação de $\beta$-endorfinas (analgésicos), cortisol (anti-inflamatório) e serotonina (antidepressivo) na corrente sanguínea e no líquido encefálico raquidiano; nível mesencéfalo, que ativa neurônios da substância cinzenta estimulando a produção de serotonina e norepinefrina que irão liberar endorfinas; nível de medula espinhal, que causará a ativação de interneurônios na substância gelatinosa e liberação de dinorfina (Alvarenga et al., 2014). Segundo Fischer (2000) a procaína possui efeitos como: estabilização de membranas, antiarrítmico, relaxamento muscular, broncoespasmolítico, melhora perfusão coronariana, efeitos inotrópico e cronotrópico negativos, anticonvulsivante, anti-histamínico, anti-inflamatório, simpaticolítico, parassimpaticolítico, vasodilatação de vasos.

O Tendão Calcâneo Comum (TCC) é composto por tendões de inserção que surgem do músculo gastrocnêmico, do músculo superficial dos dedos, e de um tendão comum originário dos músculos bíceps femoral, semitendinoso e grácil, que se inserem na tuberosidade calcânea do tarso (Noriega, et al., 2009). Esse grupo muscular possui função de flexão da articulação fêmoro-tíbio-patelar, extensão da articulação do tarso e flexão dos dígitos (Raiser, 2001; Schmitt, 2013). A ruptura total ou parcial do TCC é uma lesão tendínea de grande incidência nos cães (Costa Neto et al., 1999), principalmente em raças como Dobermann Pinscher e Labrador Retriever, sendo comumente causado por trauma direto, objetos cortantes, exercício excessivo gerando grandes disfunções locomotoras (Costa Neto et al., 1999; Neuwald \& Lamberts, 2006; Noriega et al., 2009; Raiser, 2001; Schmitt, 2013). A ruptura total pode ocorrer quando o animal apresenta postura plantígrada ao tenta apoiar o membro acometido, e na palpação é identificado os cotos rompidos, podendo ter ferida externa (Schmitt, 2013).

Os sinais clínicos mais comuns da ruptura são edema e dor na região, claudicação e falta de apoio do membro afetado (Fossum, 2014; Schmitt, 2013), hiperflexão do tarso, hiperextensão da articulação fêmoro-tíbio-patelar e o animal assume posição plantígrada onde apoia o membro afetado na superfície plantar do metatarso (Neuwald \& Lamberts, 2006; Noriega et al., 2009; Richter, 1991; Schmitt, 2013). A dor afeta o bem-estar animal, devido a ativação da resposta ao estresse, que reduz a imunidade do animal e pode ter o agravamento de afecções (Braga \& Silva, 2012).

O diagnóstico se dá pela avaliação clínica, onde pode ser observada alteração de postura do animal, edema palpável na região afetada e pela palpação do tendão calcâneo comum, pode sentir a flacidez do tendão devido a hiperextensão do tarso, não sendo necessário exames complementares para a confirmação do diagnóstico (Bloomerg, 1998; Fossum, 2014; Neuwald \& Lamberts, 2006; Schmitt, 2013). Radiografias nas projeções craniocaudal e mediolateral podem ser usadas para determinar a presença ou ausência de avulsão óssea da tuberosidade calcânea e presença de fragmentos ósseos (Fossum, 2014). Conforme o que se encontra na literatura o único tratamento para ruptura do TCC disponível é cirúrgico, através de técnicas de tenorrafia (Fossum, 2014).

\section{Relato de caso}

No dia 23/03/2018 foi atendido no Centro de Estudos em Clínica e Cirurgia de Animais (CECCA) da PUC Minas na Cidade de Betim - Minas Gerais MG, um canino, fêmea, da raça Dobermann, com 1 ano e 4 meses de idade. Segundo relatado pelo tutor o animal não apoiava o membro pélvico esquerdo (MPE) devido um acidente ocorrido há uma semana em uma grade de arame que causou um ferimento na parte mais distal no membro. Não apresentava alteração de ingestão de alimento ou hídrica.

Ao exame clínico o animal apresentava estado geral bom, animal em alerta, hidratado, com mucosa oral normocorada, sem aumento de linfonodos, TPC $<2$, frequência cardíaca (FC) de 120 batimentos por minuto (BPM), temperatura retal de $38,6^{\circ}$. Na avaliação ortopédica, observou-se falta de apoio do peso no MPE e dificuldade em caminhar, apresentando claudicação severa. Em estação, o animal apresentou hiperflexão társica e hiperextensão do joelho apoiando o membro de forma plantígrada (Figura 1). Na palpação, o animal apresentou desconforto, aumento de sensibilidade à dor na região afetada e flacidez dos cotos do tendão, a lesão cutânea já estava cicatrizada. 
Após anamnese e exame clínico foi levantada a suspeita de ruptura do Tendão Calcâneo Comum. No mesmo dia foi realizado exame radiográfico da região do Tarso do MPE, nas projeções craniocaudal e mediolateral, nas quais não foram visualizadas alterações, não sendo identificado avulsão da inserção do tendão ao osso ou fratura por avulsão da área óssea e ausência de fragmentos ósseos. A literatura indica que o diagnóstico é clínico, e neste caso foi realizado o RX para descartar qualquer alteração óssea concomitante. Foi iniciada a Terapia Neural no mesmo dia com aplicação de cloridrato de procaína a $0,7 \%$ em pontos no local da lesão e em pontos de acupuntura: B 60 (Figura 2), VB 34 (Figura 3), E 36 (Figura 4).

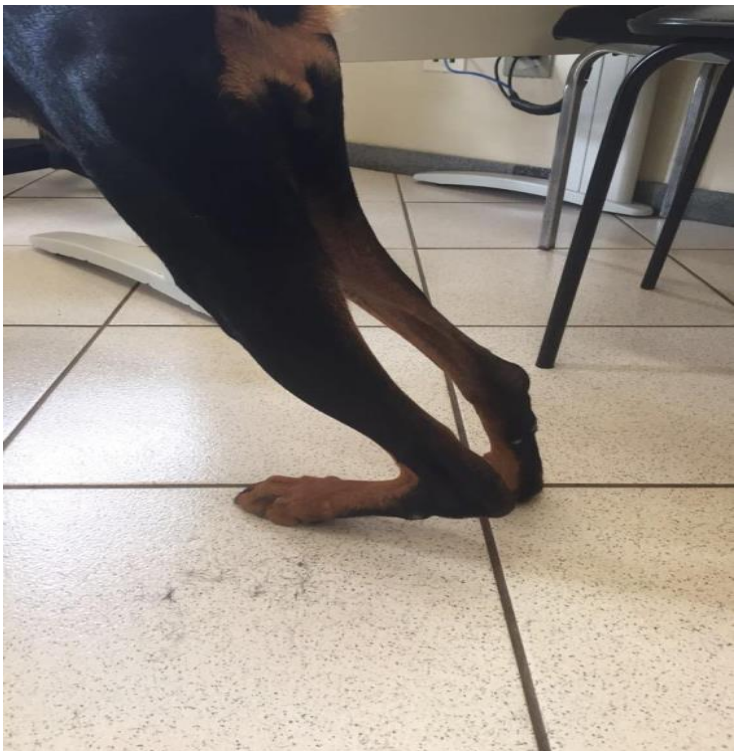

Figura 1. Canino apoiando o membro pélvico esquerdo de forma plantígrada. 23/03/2018.

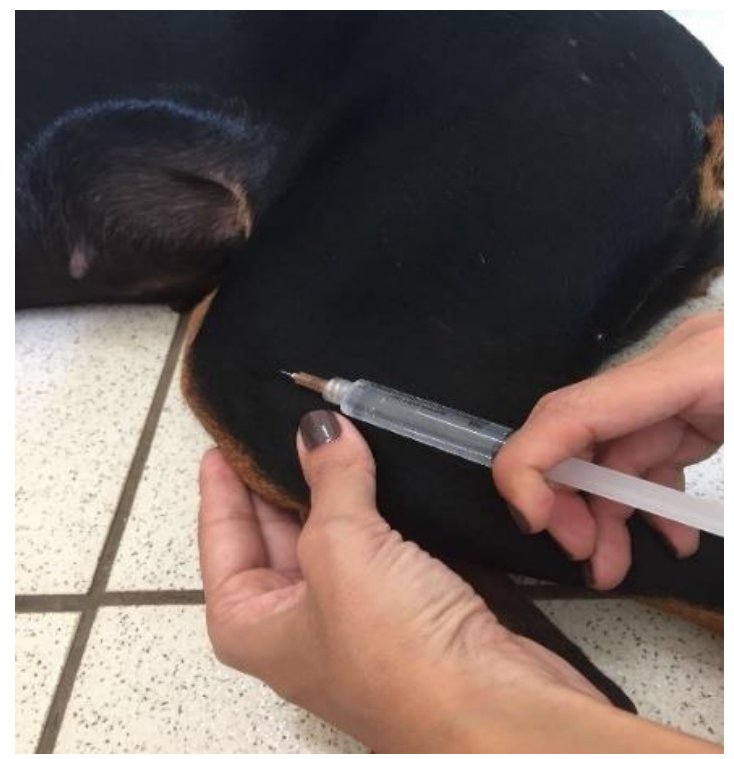

Figura 3. Aplicação de cloridrato de procaína a $0,7 \%$ no acuponto VB 34

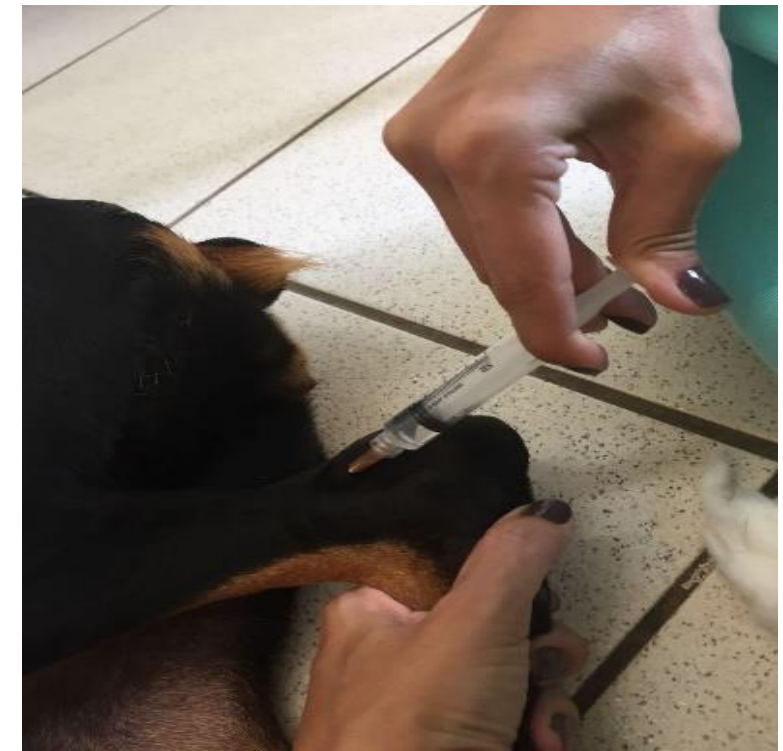

Figura 2. Aplicação de cloridrato de procaína a $0,7 \%$ no acuponto B 60.

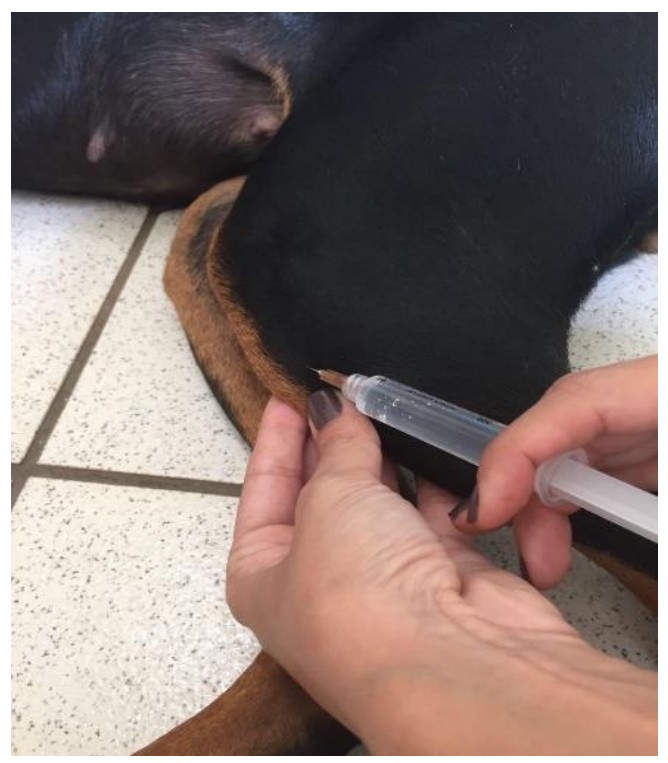

Figura 4. Aplicação de cloridrato de procaína a $0,7 \%$ no acuponto E 36

No dia 06/04/2018 animal retornou ao CECCA para avaliação clínica com o ortopedista. O animal apresentou claudicação moderada e não apoiava o MPE quando em movimento. Em estação o animal apresentava menor grau de hiperflexão társica e hiperextensão do joelho quando comparado à condição anterior, apoiando o membro nas extremidades distais das almofadas plantares. Na palpação apresentava flacidez moderada dos cotos do tendão calcâneo comum, edema regional, dor e presença de tecido fibroso no local. Após avaliação clínica, com as alterações citadas acima, juntamente com a palpação do TCC foi confirmado o diagnóstico de ruptura total do tendão calcâneo comum do MPE. Tendo em vista a grande melhora e evolução do caso e devido ao temperamento agitado do animal, o que 
dificultaria o pós-operatório, foi recomendado pelo ortopedista dar continuidade ao tratamento com o uso da Terapia Neural.

Em seguida o animal foi reavaliado pela Terapeuta Neural e Acupunturista, no qual pode observar melhora significativa da lesão com melhor apoio do MPE com flacidez moderada do tendão e presença de tecido fibroso na região. No mesmo dia foi realizada a segunda sessão de Terapia Neural, repetindo os mesmos locais de aplicação e mesma dosagem.

No dia 20/04/2018 ao exame clínico foi observado uma melhora significativa do quadro, ausência de claudicação e dor, e o animal apresentava posição anatômica com apoio completo do MPE (Figura 5). Foi realizada a terceira sessão da TN.

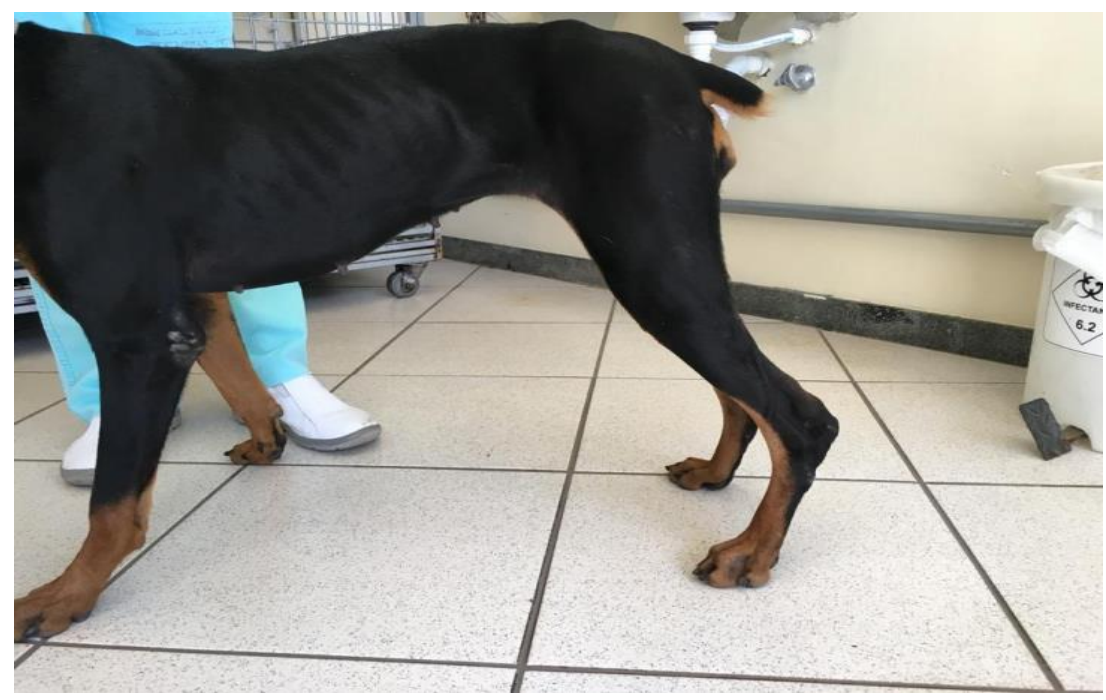

Figura 5. Posição anatômica com apoio completo do MPE. 20/04/2018

Após mais de um ano do final do tratamento da ruptura do TCC o animal foi reavaliado pelo ortopedista, que após avaliação clínica e palpação do TCC, confirmou completa cicatrização do tendão da região afetada. Foi realizado exame ultrassonográfico, onde o resultado mostra completa cicatrização tendínea, com presença de quantidade moderada de tecido cicatricial mineralizado e desorganizado no local da ruptura e aumento da espessura do TCC esquerdo em comparação com o direito (Figura 6). Ao longo desse tempo até a realização da ultrassonografia, o animal ficou bem sem sinal de dor, e se formou um tecido resistente. Podemos comprovar a eficácia da técnica nesse caso.

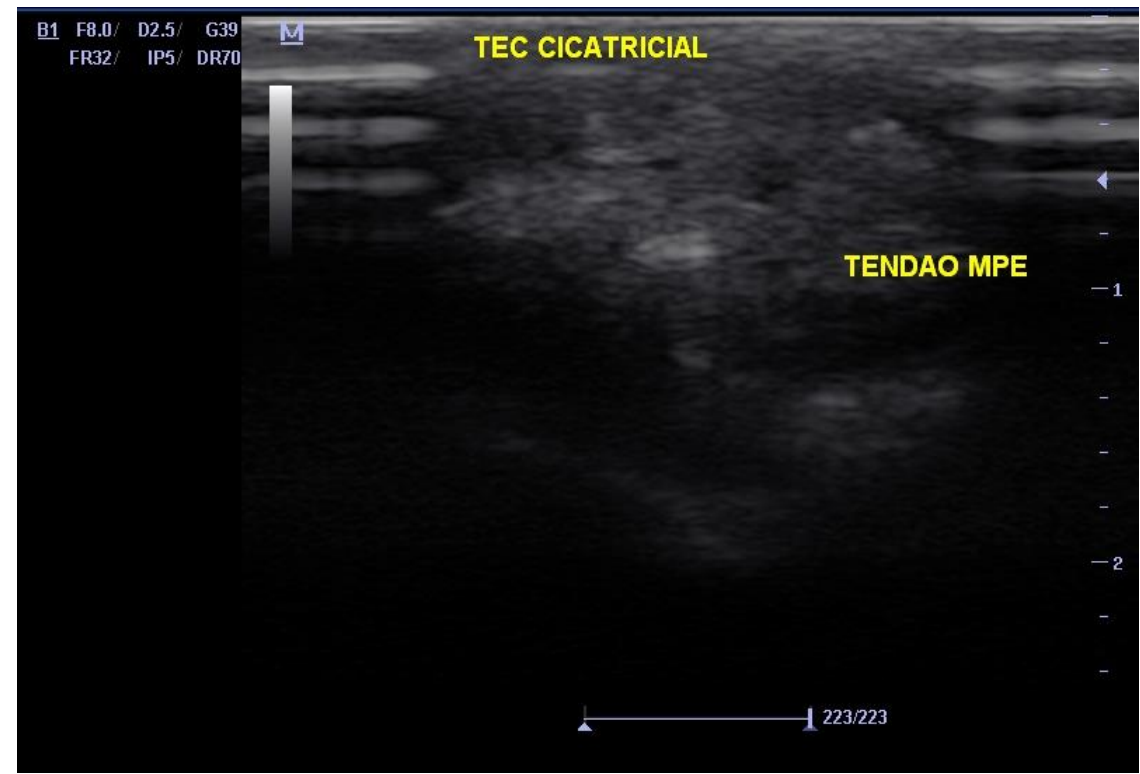

Figura 6. Imagem ultrassonográfica evidenciando o tecido cicatricial do TCC. 


\section{Discussão}

A ruptura total do Tendão Calcâneo Comum pode ser diagnosticada quando o animal apresenta postura plantígrada ao tentar apoiar o membro acometido e na palpação são identificados os cotos rompidos (Schmitt, 2013). A TN é utilizada para eliminar problemas causados por diversos fatores, e se baseia na utilização de anestésicos locais com baixas concentrações, que agem na reorganização do funcionamento fisiológico e da atividade da membrana celular (Koval, 2014). É uma técnica na qual tem também ação direta no local da lesão melhorando o fluxo sanguíneo e a ação anti-inflamatória, desencadeada pela procaína (Burrel, 2008).

Os sinais clínicos mais comuns da ruptura de tendão calcâneo são dor, edema, claudicação e falta de apoio do membro afetado (Schmitt, 2013; Fossum, 2014), hiperflexão do tarso, hiperextensão da articulação fêmoro-tíbio-patelar, levando o animal a assumir posição plantígrada apoiando o membro afetado na superfície plantar do metatarso (Richter, 1991; Neuwald \& Lamberts; Noriega, et al., 2009; Schmitt, 2013). No caso relatado foi observado uma melhora significativa da redução dos sinais de inflamação como dor, rubor e calor desde a primeira sessão de Terapia Neural. Ao final da terceira sessão de TN o animal apresentava completa ausência de dor local à palpação.

Conforme Silva, 2013 o reconhecimento da dor é de extrema importância nas espécies humana e não humanas e deve-se instituir uma terapia de suporte adequada para o alívio da dor a fim de reduzir o estresse causado pelas diversas patologias, para que se obtenham bons resultados e até mesmo a cura do paciente. Após a primeira sessão o animal apresentou melhora clínica significativa, onde à palpação pode-se perceber diminuição da sensibilidade a dor e retorno da posição anatômica do membro afetado. A dor afeta o bem-estar de um animal, devido a ativação da resposta ao estresse, que reduz a imunidade do animal agravando as afecções (Braga \& Silva, 2012). Com base na literatura o único tratamento para ruptura total do TCC disponível é cirúrgico, através de técnicas de tenorrafia (Fossum, 2014). Mas por questões financeiras e a rápida resposta já na primeira sessão de TN o tutor optou por o tratamento paliativo. Pode se observar que a TN consiste numa técnica segura e eficaz.

\section{Considerações finais}

A Terapia Neural é uma técnica ainda pouco conhecida no Brasil, mas vem sendo disseminada cada vez mais devido a obtenção de resultados positivos. Por ser minimamente invasiva se torna uma técnica segura além de ser autorreguladora e busca reequilibrar o organismo.

Pôde-se demonstrar o benefício da Terapia Neural como forma de tratamento da ruptura do Tendão Calcâneo Comum, onde o tratamento primordialmente é realizado com procedimento cirúrgico, tendo um pós-operatório complicado, alto custo e grandes chances de ruptura dos pontos cirúrgicos em animais de grande porte e com temperamento agitado.

\section{Referências bibliográficas}

Alvarenga, T. F., Amaral, C. G., \& Steffen, C. P. (2014). Ação da acupuntura na neurofisiologia da dor: revisão bibliográfica. Revista Amazônica Science \& Health, 2(4), 29-36.

Bloomerg, M. (1998). Músculos e tendões. In D. Slater (Ed.), Manual de cirurgia de pequenos animais (pp. 2351-2378). Manole Ltda.

Braga, N. S., \& Silva, A. R. C. (2012). Acupuntura como opção para analgesia em veterinária. PUBVET, 6, Art-1429.

Burrel, S. E. (2008). Salud, enfermaria y terapia neural.

Castro, R. A. (2011). Bases para la terapia neural em caninos y felinos. Dunken.

Costa Neto, J. M. da, Daleck, C. R., Alessi, A. C., \& Braccialli, C. S. (1999). Tenoplastia experimental do calcâneo em cães com peritônio bovino conservado em glicerina. Ciência Rural, 29(4), 697-703. DOI: https://doi.org/10.1590/S0103-84781999000400021

Cruz, Y., \& Naffah, R. F. (2011). Microtúbulos y terapia neural: propuesta de una investigación promisoria. Revista Med de La Facultad de Medicina, 19(1), 82-92.

De La Roche, J. C. P. (1981). La Medicina Biologica: Una Medicina no Comprometida. 
De La Torre, F. T., \& Bonilla, L. B. P. (2012). Los principios de la terapia neural desde los fundamentos del nervismo hasta la neurociencia actual. Revista de La Universidad Industrial de Santander, 44(2), 57-65.

De la Torres Rosés, M. M., \& Mendoza, R. L. (2008). La terapia neural: una alternativa en el tratamiento de la litiasis renal. Revista Archivo Médico de Camagüey, 12(2).

Draehmpaehl, D., \& Zohmann, A. (1997). Acupuntura no cão e no gato: princípios básicos e prática científica. Roca.

Fischer, L. (2000). Terapia Neural, según Huneke. Fundamentos, técnica, aplicación práctica. Hippokrates Verlag Stuttgart. 272p. DOI: https://doi.org/10.31533/pubvet.v13n7a363.1-6

Fossum, T. W. (2014). Cirurgia de pequenos animais (4th ed., Vol. 1). Elsevier Brasil.

Gonçalves, B A L, Vianna, L. R., \& Andrade, C. C. (2019). Terapia Neural no tratamento do megaesôfago congênito em cão - relato de caso. PUBVET, 13(9), 1-6. DOI: https://doi.org/10.31533/pubvet.v13n9a415.1-6

Gonçalves, B. A. L., Vianna, L. R., Fernandes, A. L., Teixeira, A. C. B., \& Amaral, K. P. (2019). Tratamento com Terapia Neural em cão com sequela de cinomose: Relato de caso. PUBVET, 13(7), 1-6. DOI: https://doi.org/10.31533/pubvet.v13n7a363.1-6

Guzmán-Blanco, M., Mejía, C., Isturiz, R., Alvarez, C., Bavestrello, L., Gotuzzo, E., Labarca, J., Luna, C. M., Rodríguez-Noriega, E., \& Salles, M. J. C. (2009). Epidemiology of meticillin-resistant Staphylococcus aureus (MRSA) in Latin America. International Journal of Antimicrobial Agents, 34(4), 304. DOI: https://doi.org/10.1016/j.ijantimicag.2009.06.005

Illera, J. C. J., \& Cárdenas, M. L. (2011). Procaína, epigenética y terapia neural en el cáncer,i una alternativa terapéutica? Revista Médicas UIS, 24(2), 173-180.

Koval, P. R. (2014). Medicina para o ser singular com dor persistente ou outros problemas complexos. Ediciones incertidumbre.

Molano, M. L. B., Bonilla, L. B. P., Dussan, E. H. B., \& Londoño, C. A. V. (2014). Anatomo-functional correlation between head zones and acupuncture channels and points: a comparative analysis from the perspective of neural therapy. Evidence-Based Complementary and Alternative Medicine, 2014, 1-18. DOI: https://doi.org/10.1155/2014/836392

Neuwald, E. B., \& Lamberts, M. (2006). Avulsão do tendão calcâneo comum em cão-Relato de caso. Revista Da FZVA, 13(2), 116-126.

Noriega, V., Lamberts, M., Correa, R. K. R., Gianoti, G. C., Pignone, V. N., Alievi, M. M., \& Contesini, E. A. (2009). Tenectomia parcial como tratamento para estiramento crônico do tendão calcâneo em cão. Acta Scientiae Veterinariae, 37(4), 383-387. DOI: https://doi.org/10.22456/1679-9216.16417

Radlinsky, M. G. (2015). Cirurgia do sistema biliar extra-hepático. In T. W. Fossum (Ed.), Cirurgia de pequenos animais (pp. 476-487). Elsevier.

Raiser, A. G. (2001). Reparação do tendão calcâneo em cães. Ciência Rural, 31(2), 351-359. DOI: https://doi.org/10.1590/S0103-84782001000200027

Richter, R. K. (1991).72f. Estudo da cicatrização do tendão calcâneo comum com implante de fibra de carbono no cão. Tese (Pós-Graduação). Universidade Federal do Paraná para a obtenção do título de Mestre em Ciências Veterinária.

Schmitt, B. (2013). 23f. Ruptura do tendão calcâneo comum em cão: Relato de caso. Monografia (PósGraduação). Centro de Estudos Superior da Fundação Educacional Jayme de Altavila Especialização em Clínica Médica e Cirurgia de Pequenos Animais.

Vianna, L. R., \& Gonçalves, B. A. L. (2016). Nasce uma nova especialidade na Medicina Veterinaria Brasileira: Terapia Neural e Odontologia NeuroFocal. Revista Veterinária e Zootecnia, 130, 16-21.

Vianna, L. R., \& Gonçalves, B. A. L. (2017). Entenda a terapia neural. Revista CFMV, 74, 44-47.

Recebido: 9 de março, 2020.

Aprovado: 6 de abril, 2020 .

Disponível online: 3 julho, 2020.

Licenciamento: Este artigo é publicado na modalidade Acesso Aberto sob a licença Creative Commons Atribuição 4.0 (CC-BY 4.0), a qual permite uso irrestrito, distribuição, reprodução em qualquer meio, desde que o autor e a fonte sejam devidamente creditados. 